\title{
Living but Leaving: Therapy in Light and Right of Life and Death in Traditional-Cum-Contemporary Societies
}

\author{
Dr. Geoffrey Wango ${ }^{1} \&$ Dr. Gidraph Wairire ${ }^{2}$ \\ ${ }^{1}$ Department of Psychology, University of Nairobi, Kenya \\ ${ }^{2}$ Department of Sociology and Social Work, University of Nairobi, Kenya \\ Correspondence: Dr. Geoffrey Wango, Department of Psychology, University of Nairobi, Kenya
}

Received: October 9, 2018

Accepted: October 30, 2018

Online Published: November 16, 2018

doi:10.5539/ijps.v10n4p79

URL: https://doi.org/10.5539/ijps.v10n4p79

\begin{abstract}
Dealing with death can be demanding and anxiety provoking for counselling practitioners. There is need to focus on therapeutic strategies aimed at assisting persons deal with loss and grief. This paper explores the concept of death in traditional-cum-contemporary societies, particularly within the prevailing context of increasing death rates due to natural factors, accidents, and disease. In this paper, five themes were identified through narrative analysis. These are: individual understanding of death, socio-cultural communal meaning of death, role of religion, development in science and advancement in information seen as vital in understanding of death, and application in counselling and therapeutic support services. Overall emphasis in this paper is the need for therapists and social workers to understand death in both the prevailing culture and transcending into modern discourse in order to find meaning in life.
\end{abstract}

Keywords: death, perception of death, counselling, traditional-cum-contemporary society

\section{Background}

Dealing with death can be a demanding experience loaded with anxiety for clients seeking counselling. This is highly significant in dealing with bereavement after the latest Diagnostic Statistical Manual [DSM-5] (American Psychiatric Association, 2013) removed the bereavement exclusion. Subsequently, an exception could only be made for clients with major depressive disorder (MDD) in certain cases; for example, if the patients were psychotic, suicidal, or severely impaired. The main reason is the fact that depressive syndromes in the context of bereavement are not fundamentally different from depressive syndromes after a major loss (Zisook et al., 2012). But at the same time, the DSM-5 (American Psychiatric Association, 2013) takes cognizance of two significant aspects, specifically for this paper: (1) there are substantial differences between bereavement and major depressive disorder; and, (2) an expectable or culturally approved response to a common stressor or loss, such as the death of a loved one, is not a mental disorder. Subsequently, there is an utmost need among counselling practitioners to focus on therapeutic strategies aimed at assisting persons deal with loss, grief and bereavement.

Therapists are part of the community of clients; they work with clients in their own setting. Imbedded and espoused as is life, death too is inevitable and for most people, the emotional impacts of the negative experiences of death far outweigh positive experiences of life. However, there is also ambivalence about evolving perception of death especially with advancement in medicine and technology in which the role of professionals, such as medical doctors, surgeons, mental health service providers including clinicians, psychologists, social workers and the clergy can assist clients dealing with death related issues including loss, grief and bereavement. In addition, synthesizing research on death is often precluded in traditional-cum-contemporary societies thus hindering social, health and scientific progress as well as societal impetus to integrate effective therapy to deal with loss and grief. Yet within the life and death dichotomy that exemplifies our existence, life success hinges on the ability to overcome and respond constructively to the fear and anxiety of death. The paradox of death is a challenge that clients must learn to accept, for death is inextricably interwoven into our lives.

This paper hinges on enhanced understanding of the causes, consequences and underpinnings of death. Effective therapy must therefore explore and focus towards attaining a comprehensive understanding of the phenomena encountered in professional practice, such as the concept of death in traditional-cum-contemporary societies. The use of the concept 'traditional-cum-contemporary societies' is intended to mean that the societies are largely in 
transition and that they have aspects of traditional combined with contemporary systems. An examination of these systems involves an exploratory stance and openness to the complexity of death, particularly within the prevailing context of increasing deaths as a result of natural factors, accidents, illness and disease. Five themes were identified through narrative analysis and they are aligned with the topics in this paper as follows:

Table 1. Thematic Perspectives and Conceptualisation

\begin{tabular}{|c|c|c|}
\hline & Theme & Topics in Paper \\
\hline 1 & Individual conceptualisation of death & $\begin{array}{l}\text { Deal or dealing with death: The Meaning and Value of } \\
\text { Life and Death }\end{array}$ \\
\hline 2 & Socio-cultural understanding of death & Death and meaning of life in Socio-cultural and Communal \\
\hline 3 & $\begin{array}{l}\text { Role of religion and faith based } \\
\text { perspectives of life and death }\end{array}$ & $\mathrm{cc}$ \\
\hline 4 & $\begin{array}{l}\text { Development in science and } \\
\text { information technology seen as vital in } \\
\text { understanding of death }\end{array}$ & $\begin{array}{l}\text { Death in Clinical Practice: The Meaning and Value of life } \\
\text { vis-à-vis death print }\end{array}$ \\
\hline \multirow[t]{2}{*}{5} & \multirow{2}{*}{$\begin{array}{l}\text { Counselling and therapeutic support } \\
\text { services in traditional-cum-modern } \\
\text { societies }\end{array}$} & $\begin{array}{l}\text { Our existence-life and death, our undeniable destiny and a } \\
\text { thrilling future }\end{array}$ \\
\hline & & $\begin{array}{l}\text { Distance yet so aptly Present: Therapeutic Practitioners, } \\
\text { Practice and Death }\end{array}$ \\
\hline
\end{tabular}

It should be noted that there are variations in the community perspectives of life and death. This is essentially because various societies even among traditional societies have diverse customs. Notwithstanding all factors, the concept of life and death also serves as a means of understanding the way of life, psychology and philosophies of various communities.

\section{Hermeneutic Phenomenology Approach}

The hermeneutic phenomenology approach adopted in this paper transcends the socio-cultural and historical structure and allows a psychological reorientation of the life - death experience (Dobrosavljev, 2002; Dreyfus, 1991; Laverty, 2003; Trisel, 2015). Sloan and Bowe (2014) posit that phenomenology is an examination of the human experience and subsequent behaviour. Also, the focus in hermeneutic phenomenology is not to control human experience such as life and death; instead, the approach aims at understanding experiences from the personal vantage point (Kafle, 2013). The focus on the personal experience allows both an exploration of that experience as well as an analysis of the socio-cultural structures. In the context of this paper, the hermeneutic approach considers the weaving between traditions (culture, customs and religion) and modernity, while at the same time accepting the need for the authentic self in context. This approach seeks to uncover the traditions about life and death, as well as champion a genuine vantage to deal with the finitude of death.

Further, the hermeneutic approach requires that participants have an understanding of self (Malet, 2013). In essence, this is not about the dominant culture nor is it an imposition upon the individual or community. Consequently, there is a sense of understanding about life and death at both individual and community levels, and this is inculcated in the cultural (traditions and religion) perspectives of various communities in Africa. This understanding includes self and community. It is based on a sense of understanding of their experiences (Nicholl, Loewenthal, \& Gaitanidis, 2016). Therefore, hermeneutics describes the interpretation of life and death experience (Sloan \& Bowe, 2014). This is because the life and death experience are a result of the cultural phenomena and counsellors and social workers have a major role in assisting clients deal with death.

Hermeneutic phenomenology approach considers individual lived experiences. Subsequently, this paper strives to expound the life - death phenomena and the extent to which caregivers (clinical psychologist, counsellors, psychiatrists, psychologists, social workers) respond to subsequent grief. Phenomenology enables a focus on the phenomena such as life and death, the events being examined, as well as the nature of their meaning (Finlay, 2009; Kafle, 2013). Using the hermeneutic phenomenology (van Manen, 2007) as our framework of reference, we have attempted to develop several themes regarding the life - death experience and made some efforts to appropriately contextualize them in the traditional-cum-contemporary society. Additionally, by acknowledging the traditional experiences about life and death, we have made some attempts to re-cast experiences into modernity and thus seek their integration in therapeutic practice, rather than simply highlight the modern 
technological advancement which would have been deemed superior and the more predominant culture. Instead, the hermeneutic phenomenological approach offers a balance in developing a culturally informed practice for counselling and social work practitioners. It is therefore possible to hopefully reintroduce strategies arising out of a meaning of the life death experience.

\section{Deal or dealing with death: The Meaning and Value of Life and Death}

As a counselling psychologist and a social worker, it is challenging, if not impossible for us to discuss death arising out of the untenable position of life vis-à-vis death. This is because of the precariousness (that is both in value and mystery) of life that underlies all clinical disciplines including clinical psychology, counselling, psychiatry, psychology, psychotherapy and social work. It is even more admonishing to discuss death in the more traditional societies. This is not because death was rare or non-existent in traditional living. On the contrary, the number of deaths in the more traditional societies in developing countries has increased tremendously due to fatal accidents, diseases such as HIV and AIDS and cancer among others, suicide, war, terrorist attacks and other natural factors. Yet death still remains a mystery. The fear and anxiety as to why death hits so hard and leaves wanton devastation, loss and grief on people may be found in seeking a meaning and value of life and death. A counselling psychologist, social worker and other persons seeking the meaning and value of death is somehow albeit trying to strike a deal for dealing with death. Finding the meaning and value of life and death would require several philosophical realms, including culture, religion and underpinnings in philosophy. This is our starting point though it is not possible to explore all the philosophies and their interpretations and implications.

The preservation of life is a paramount clinical goal and as Byock (2002) states, perhaps and understandably, for clinicians death is the enemy to be conquered. Clinicians need to be joined by others such as counsellors and social workers. So how do we deal with death, or is death already a deal, which takes us to the title of this paper; living or leaving, life or death, right or light. But death and death anxiety are complex constructs (Dadfar \& Lester, 2017; Firestone \& Catlett, 2016; Pashak et al., 2018). Death anxiety is the dread of death, the associated emotions linked with death (Dadfar \& Lester, 2017; Rice, 2009) also referred to as thanatophobia (fear of death) and necrophobia (fear of death or the dead), the anguish, actual and/or anticipated loss (Byock, 2002; Dadfar \& Lester, 2017; Peters, Cant, Payne et al., 2013).

There must be a balance between life (being) and death (finitude). This is because although life and death appear as two opposite or contrasting ideas, they are somehow connected though seemingly opposed to each other. In addition, each of them is an entity that contains multiple sub-levels. This can be demonstrated as follows:
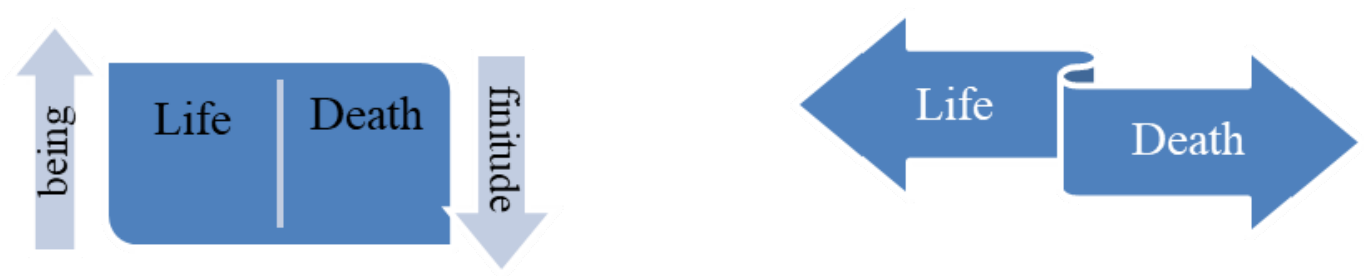

Figure 1. Life Death mutual complementarity

It is evident that being is life, and the finitude of life is death. Nonetheless, one can argue that life and death are on two opposite (opposing) ends. Counselling psychologists along with clinicians and others including social workers must therefore ask what death represents (Nzioka, 2000), including seeking a meaning for life, because as long as there is life on one end, death is anticipated on the last end.

Psychologists including Sigmund Freud and Viktor Frankl as well as others (Becker, 1973; Heidegger, 1962, 1976; Young, 2003) have investigated the meaning of life and death. Byock (2002: 279) summarises the phenomenon of death:

Phenomenologically, death is nonbeing. The essential nature of life entails activity, purpose, and making order from disorder. Death is the antithesis of life. Nonlife is inactive, and despite its stillness, death is chaos. Life generates its own meaning. In contrast, on its face death appears devoid of meaning and value.

For the purpose of this paper, we have focused on the psychology and philosophical attributes of death in traditional-cum-contemporary societies. This includes a meaning of life as well as examining the certainty about 
death. We must accept that life itself is meaningful to all societies, but the certainty of death is somewhat different because of diverse interpretations. Nevertheless, it is apparent that the fact of death profoundly impacts on all human beings. Perhaps our focus then should be, and will be informed by the understanding of the meaning of life and how death 'fits' in the mix. We call it mix because although it may be ignored (rather assumed), life has an unknowable relationship with death; life and death exist in mutual complementarity (Figure 1) - for we live and die, we are either alive or dead. Byock (2002: 279) concludes as follows:

Death is central to the meaning and value of human life as experienced by individuals and by communities. Death does not give meaning to life, but does provide the backdrop against which life is lived.

This relationship between life and death is essential to our understanding of therapeutic relationship and has a profound effect in the client-counsellor relationship in traditional societies where death is a mystery and has a lot of anxiety. In fact, at times death appears as pure darkness and yet we refuse to shed light on it. For counselling psychology, social workers and other helping professionals, death need not be as enigmatic especially with the development of knowledge on loss and bereavement as postulated by Elisabeth Kübler-Ross (Kübler-Ross \& Kessler, 2005).

The fear of death is relatively sturdy and hence the emotions are powerful. There is not one organ or gland that is distinctively 'responsible for' emotion, including strong emotions associated with death. The entire brain is involved, but the signals that form emotions are integrated and interpreted by parts of the limbic system. This may explain the various emotional outlets associated with loss and death such as crying, shaking, numbness, shock and anger (Kübler-Ross \& Kessler, 2005). Yet fear is a feeling experienced when individual encounters or think about anything or anyone that can harm them. Fear is characterized by its orientation to the future because of the threat (sometimes with no means of escape to avoid it such as death in old age or serious ailment), and hence death is so fearful to the extent that it can be a preoccupation. This could explain why many people are both cautious and conservative about death; death acquires a functional value in that it is a permanent feature since it is a part of life but again is not set off too easily or too slowly since it is not as predictable. Thus, it is possible that death may not be as apparent in young ages though increasingly threatening (and thus more afraid) in acute cases such as ailing health or old age. This is why death causes both fear and anxiety. Fear and anxiety are seemingly similar, yet they are important to differentiate especially in psychology (American Psychiatric Association, 2000) because these emotions can transform into certain behaviours including over use of defence mechanisms. This is what obscures the recognition of the reality of death. In addition, fear and anxiety are essential to the dynamics of emotional illness and hence the death anxiety (Byock, 2002; Dadfar \& Lester, 2017; Peters, Cant, Payne et al., 2013; Rice, 2009) needs to be linked to positive mental health (Holtmaat et al., 2018; Keyes, 2005; Ryff \& Singer, 1998).

Psychology must therefore illuminate life, and hence provide sufficient knowledge to assist in giving a purpose to life and in turn assist in overcoming fear and anxiety associated with death. This is by explaining life and death, and in therapy assisting to resolve the life-death crisis. Death then is in the background of life, and death from this perspective must not overcome life but give value to our human experience. Psychology illuminates death to make it relevant and approachable in terms of the meaning, purpose and value of life. Similarly, social work must illuminate the social wellbeing within which this life thrives, the environment and essential factors for assisting individuals experiencing or affected by the trauma of death and associated grief. Death can then be understood in emotional and logical conceptualization. But first, we must understand death and approach it from several perspectives, that is, cultural and communal, individual, religious and communal perspectives. The next section looks at the traditional (particularly African) concept of death.

\section{Death and Meaning of Life in Socio-Cultural and Communal Context: The Concept of Life in Traditional Society Living}

African traditional societies had a philosophical orientation to life that incorporated religion, culture and traditions (Mbiti, 1969; Wango, 2015). The individual was a part of the community to which she or he belonged; everyone was a member as an individual and as part of the community. Religion and tradition were intimately interwoven. Therefore, life and death are a part of the religion and tradition, the individual and the community.

Due to this interconnectedness between culture (traditions) and religion (faith and spiritualism), the African concept of life, death and the hereafter is closely linked to, and influenced by this traditional - religion dichotomy (Figure 2). In general, life is considered important while death is not considered as a natural event but tends to be seen as, or 'caused' by some external forces such as witches, spirits or curse. 


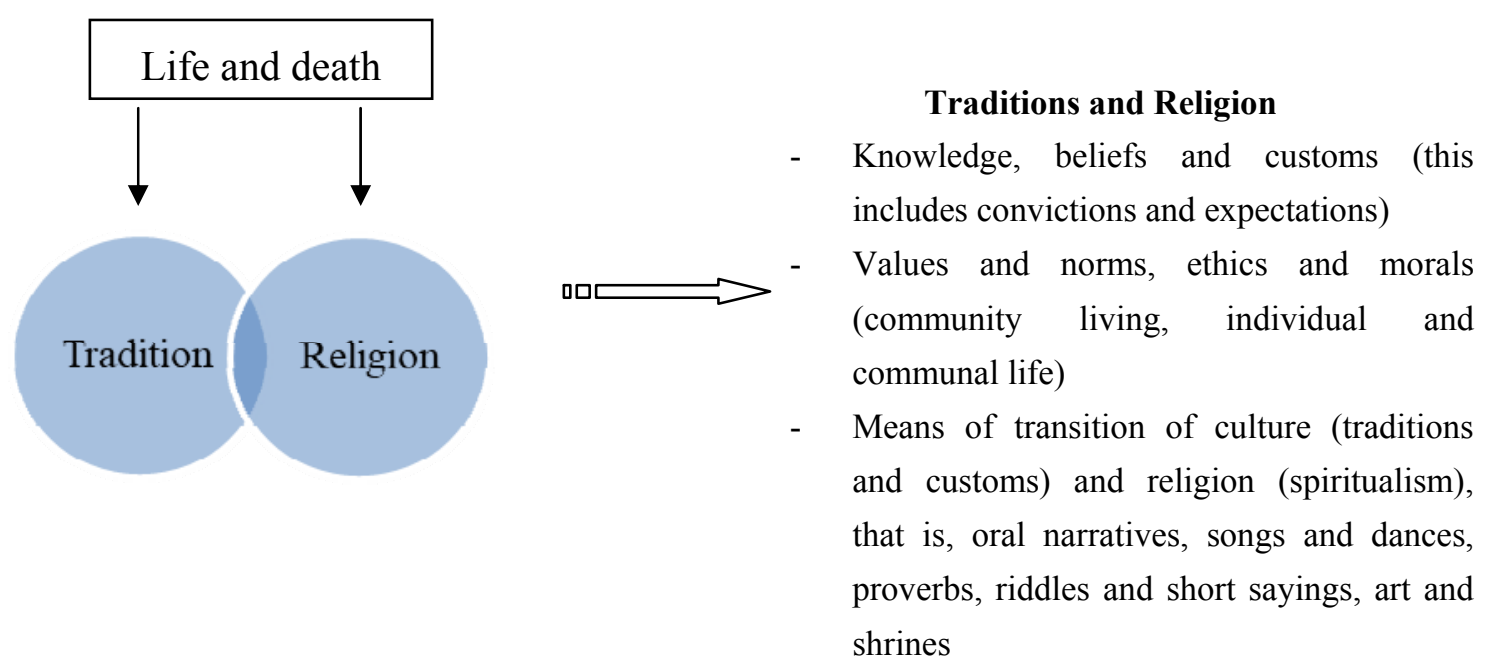

Figure 2. Traditional Psychological Philosophical Conceptualisation of Religion and Tradition

The concept of life and time in traditional societies, including Africa has been researched on in a number of perspectives (Asuquo, 2011). The concept of time plays a pivotal role in the way a society derives its values, beliefs and conceptions. One of the areas where time is of importance is when analyzing people's perceptions on death and afterlife (Asuquo, 2011; Mbiti, 1969; Wango, 2013, 2015). This is because time and timeliness merges with religion (faith, beliefs and the supernatural power of God), communal living (the us-ness, that is, one-ness), life and hereafter (children, ancestors and the spirit world). These aspects are components though related to each other. This connection can be demonstrated as follows:

Table 2. Rationalization of Religion and Traditions with God, Spirits, Communal Living and Life here and after

\begin{tabular}{|c|c|c|c|}
\hline God & Ancestors, spirit world & $\begin{array}{ll}\text { Communality } & \text { living, } \\
\text { one-ness, us-ness }\end{array}$ & $\begin{array}{l}\text { Children, life } \\
\text { hereafter }\end{array}$ \\
\hline $\begin{array}{l}\text { Supreme being, creator of } \\
\text { the universe, sustains all } \\
\text { universe, supernatural, } \\
\text { has complete control (no } \\
\text { science or rationale). }\end{array}$ & $\begin{array}{l}\text { Closer to God, 'heralders' } \\
\text { - gone ahead of us, keeps } \\
\text { link with spiritual world, } \\
\text { watches over humans. }\end{array}$ & $\begin{array}{l}\text { - } \text { Respect } r \\
\text { reverence for supreme } \\
\text { being. } \\
\text { - Communal living } \\
\text { with one another. } \\
\text { - Rituals and rites of } \\
\text { passage. }\end{array}$ & $\begin{array}{l}\text { Children are a blessing } \\
\text { and mark life hereafter. } \\
\text { They link with the spirit } \\
\text { world through naming of } \\
\text { child/ren to 'keep } \\
\text { contact' with spiritual } \\
\text { world. }\end{array}$ \\
\hline $\begin{array}{l}\text { Revered, not seen, glory } \\
\text { cannot be behold. }\end{array}$ & $\begin{array}{l}\text { The ancestors play an } \\
\text { important role in the } \\
\text { communal life. They are } \\
\text { not cut off from the } \\
\text { living, for they may still } \\
\text { reveal themselves in } \\
\text { dreams or appear to their } \\
\text { living relatives to guide } \\
\text { or correct them. }\end{array}$ & $\begin{array}{l}\text { - Person lives in } \\
\text { harmony with others in } \\
\text { the community. } \\
\text { - Observance } \\
\text { taboos, traditions and } \\
\text { customs. } \\
\text { - Curses } \\
\text { misfortunes befall anyone } \\
\text { who fails to adhere. }\end{array}$ & $\begin{array}{l}\text { Curses and misfortunes } \\
\text { are a mark of failure to } \\
\text { adhere to the will of the } \\
\text { gods (such as lack of } \\
\text { children, still birth, } \\
\text { death). }\end{array}$ \\
\hline
\end{tabular}

This relationship between God, the spirit world, community and life and hereafter (Table 2) is based on certain rules and regulations and is also part of rhythm or cycle of life. Njoku (2002) proclaims that life is a communal affair which involves a relationship and communion between humans, God, ancestors, divinities, other community members. This is aligned to Mbiti (1969) who notes that to be human is to belong to the society, and 
the whole community, and thus involved through effective participation in the beliefs, ceremonies, rituals and festivals of that community. It is possible to argue that there is a hierarchical order in supremacy (Asuquo, 2011; Njoku, 2002; Mbiti, 1969). This can be demonstrated as follows:

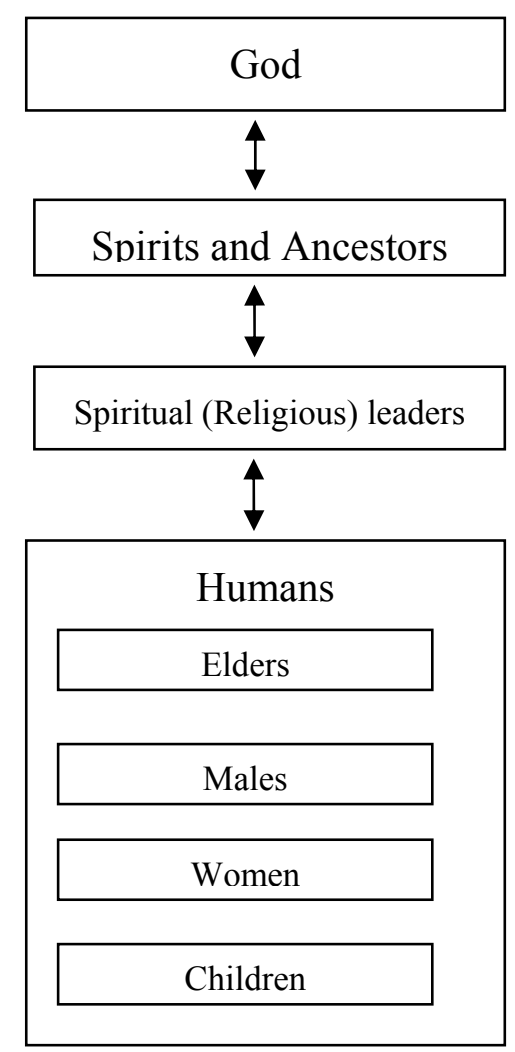

Figure 3. The Hierarchical order of Power and Influence, Dominion and Connectedness

While God is the Supreme Being, spirits and ancestor have an influence as were the spiritual leaders though with varied (lowered) influence. Humans were last in the pecking order, and still, elders had an upper hand, while males had higher preference over females with children at the lower end of the lope.

The aspects of living and individual life went through several phases from birth to death and this is in agreement with several scholars on traditional African philosophy such as Asuquo (2011), Njoku (2002), Mbiti (1969) and Wango (2013). Fuchs and Pallagrosi (2018:289) succinctly puts it thus:

Phenomenological philosophy has explored the concept of time as a basic structure of the human self. According to its perspective, human beings are time producing organisms, and their awareness of being is imbued with the sense of a lived duration of experience.

Hence the concept of human life is in direct relation to time; it is also subsumed that everyone went through the stages of life - an implied common stance. These include: puberty, initiation, marriage, procreation, old age, death and life in the hereafter (Figure 4). Death marked entry into the community of the departed and finally entry into the company of the spirits. Still, the living and the departed were in continuous connection. This process can be outlined as follows: 


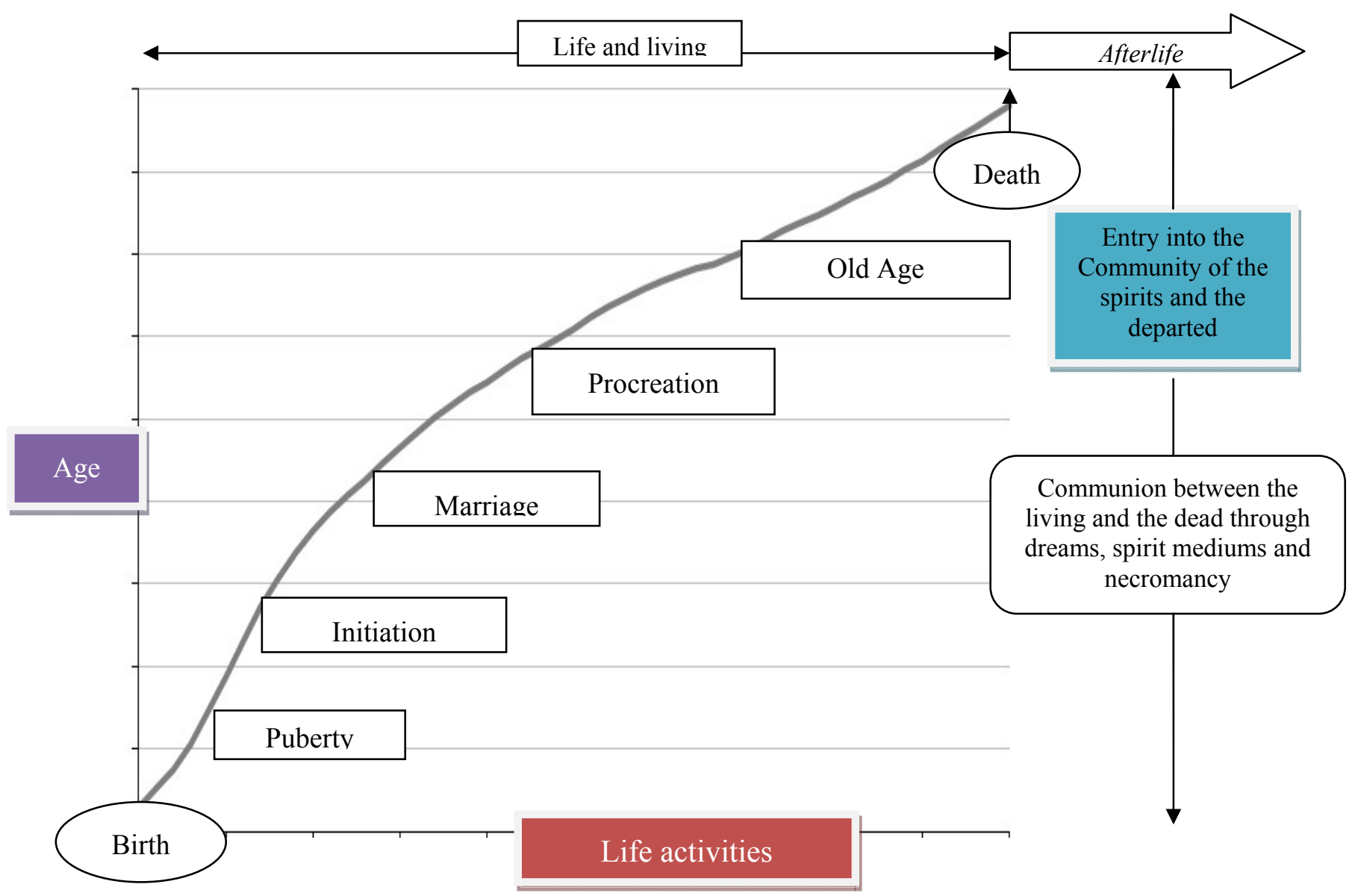

Figure 4. Time pivotal role: Life through Phases in Traditional Societies

It is evident that time in life is a series of events that starts at birth and culminates in death. Communion between the living and the dead was in several ways, particularly in naming to perpetuate life as well as through dreams and spirit. In several instances, the dead if mistreated and/or unhappy continued to appear to the living in dreams and in form of spirits. Psychologically it can be argued that the appearance in form of memory was assumed to be real rather than phenomenological representation in the human brain.

The concept of time (time now and conceptualising the future) plays a pivotal role in the way a society derives its values, beliefs and conceptions (Byock, 2002; Marava, 2015; Tillich, 1959) and hence life and death are directly linked to time as well as the people's philosophy (Figure 4). In the traditional context, the phenomenon of events may be natural, a rthymnic pattern or perchance... the diagram therefore explicates how we transcend the lifespan, and thus living and enduring trace of oneself, and at the same time adding meaning to one's life and communal living. This explains why certain rituals and traditions are virtuous actions (call them norms) in that they have and add meaningfulness to life and our finitude. We think that meaning of life comes in various degrees that have proportionate interconnectedness between traditions, religion and modernity.

Equally important to note is that in nearly all the stages expounded above, a common activity that takes place is rearing phase which may be seen as recurring across the stages. Through this, the virtues that help give meaning to life are implanted in individuals through the socialisation process. It is through this that the philosophical ideals that make life more meaningful get rooted in individuals and in their communities. Religion, traditions, norms and beliefs are passed on across generations through the same process which to a certain extent, becomes cyclical. 


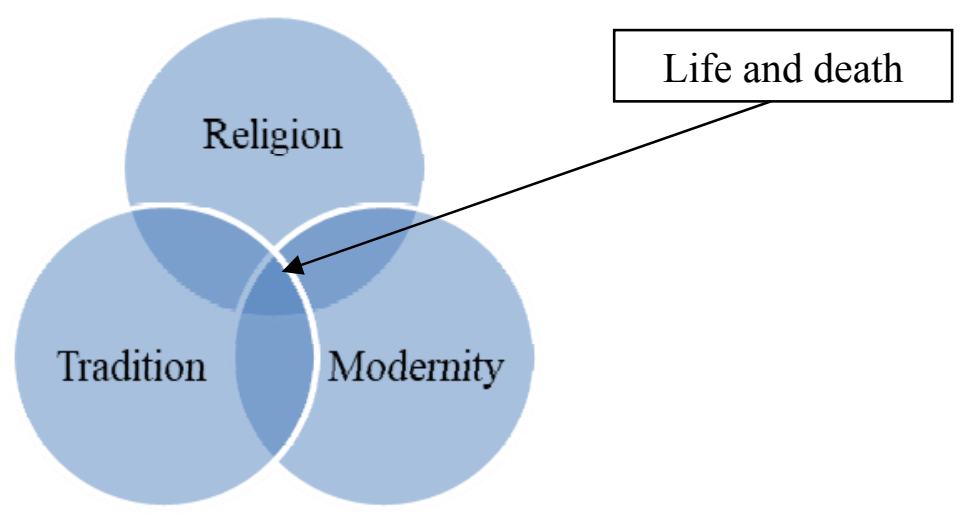

Figure 5. Death's proportionate interconnectedness with Tradition, Religion and Modernity

At the end of it all, physical life always ends at death. But death in the traditional concept is also a transition which involves transformation from the physical into the spiritual as the dead continue to live as ancestors. It follows logically that God (or the spirits) who created life also takes it through death when the time is up. The problem with this viewpoint is that it does not clearly explain whether it is God who causes premature and undesirable deaths such as those caused by suicide, war and violence, illness and accidents. Moreover, and while at it, philosophically traditional societies could debate if God deliberately inflicted such pains and sorrows that death often brings. Our guess is that this religious philosophy could be contrasted with the modern Christian faith in which God is seen as a loving father. But embedded in this life and death is also whether death is timely or caused by someone or circumstances. Subsequently, several communities had rigorous cleansing ceremonies in case someone killed another person, or worse still committed suicide. This is because though traditional societies could have somehow accepted or grasped suicide by accepting moments of frustration, failure and despair, suicide was not embraced. This was chiefly because life was revered, and hence a person could not beckon death through killing self or other (suicide or killing a relative or neighbour) - death was highly discouraged, and was an abomination.

\subsection{Death in Clinical Practice: The Meaning and Value of Life Vis-À-Vis Death Print}

The ordinary interpretation of the advancement in technology and medicine has been two-fold: that death is inevitable; and, a search for prolonging life and preventing death. This is interesting because it places the inevitability of death with the need for a cure as well as requirements for care and compassion for the most ill, elderly and dying (mortality awareness or visibility to avoid death?). This ends up as a paradox for psychologists, social workers and informal care-givers who must then reckon with therapeutic practices that must be found to comprehensively assist in such belated fate. We have the medical clinics, hospitals, hospice, nursing homes, old age residences, drugs and life-sustaining technologies but death is immune to all, a finitude. Freud (1920) is often quoted as saying that the aim of all life is death, and that inanimate things existed before living ones. Yet, and still, death has a lot of fear and anxiety, albeit arising out of the almost uncertainty of death. Crist (2018:8) elucidates the fear and anxiety in death as follows:

Anxiety is closely linked then to our human tendency to strive to grasp this mystery of death. Yet, it is not the knowledge of death which causes this striving but something more fundamental that causes us to "repress the thought of death."

Gadamer (1996) like Crist (2018) unpacks this tension, namely, the role anxiety plays in our striving for an understanding of the mystery of death, while never being able to fully comprehend this profound relationship between anxiety, life, and death. Our explanation in terms of clinical practice and the advancement in medicine and information technology most probably arises from a denunciation of death - certainly we want to prolong life and reduce the pain and grief associated with death. What then is the possibility of eliminating death? Various scholars such as Heidegger (1962; 1976), Becker (1973) and Young (2003) extensively discuss this denial of death, or what is called the "illusion of immortality. In medical practice the challenges and inevitability of death is a renewed disposition that medical professionals and would be patients ought to take cognizance. This is evident in medical explanations of the process of death. Therefore, the tension about death arises majorly out of our interpretation of life, and because of our fear and anxiety about death. Yet death is part of our human existence. 
Counselling and psychology particularly in the more traditional societies need to develop the client's own understanding of life in a meaning-making system (MSS) that has coping capacities such as resilience alongside the careful application of science, medical and information technology. Practitioners must be aware that cultural values and religious beliefs (Figures 1 and 2) tend to complicate both understanding and public discussion about death. Thus, many people are clearly skeptical about death even when it is too imminent. Subsequently, a wide range of fears about death are common among many people - they are both individual and communal. Evidently, many people provide infrequent, often inadequate, hurried and poor quality explanations for death. The inadequacy of information leads to general fear and anxiety. Yet, a positive intervention can best be done by dispelling myths about death in order to prevent unnecessary fear and anxiety.

Despite the colossal and impressive advancement in science and technology, impressive innovations in medicine and pharmacy, death remains a part of us. The feeling of uncertainty and anxiety of death has probably increased in modern society than in the more traditional societies. Psychologists and philosophers could as well pose the more logical statement - that traditional societies had resigned to the fate of death, and pose the more poignant question - is the modern society preoccupied with life and hence the desire to overcome death? This is most fascinating taking cognizance of our present world that is largely based on the more positive rational science and modern logic. The various institutions, caring services and programming including medical clinics, hospitals, hospice, nursing homes, home based care and comprehensive health care are highly significant even towards the end-of-life care. After all, death still has the final laugh as all attempts to trounce it are invalid. The role of clinicians and professionalism is best captured by Byock (2002:287) in a paper on 'the meaning and value of death' who concludes so appositely by summarising the precarious role of professionals with a caution

Acting on behalf of society, the clinical professions bear critical responsibilities for caring for those who are dying and bereaved. However, overreliance on professionals as a means of denying or distancing ourselves from death and grief can diminish the fullness and richness of living and erode the experience of meaning and value in our lives. Beyond acknowledging and honouring basic obligations, individuals, families and communities have the capacity to respond to the ultimate problem of death in a creative manner including the performance of rituals that reflect and advance values of human worth, dignity, and enduring connection. The clinical professions can lead by setting standards for excellence and by providing care that is not only competent but unabashedly loving. In so doing meaning and value is created by direct intention.

As a counselling psychologist and a social worker contextualized in a traditional-cum-contemporary societies, we too would humbly suggest an ideologist of positivism based on traditions, religion and science. This, in our view, would encompass the totality of our human evolution (in terms of culture, religion, information, science and technological advancement) thus imparting a truthfully normal arrangement of our human mind-set in order to establish harmony between philosophy and psychology. This involves a reconstruction of society characteristic of modernism based on traditions and religion, a rather realistic viewpoint.

\subsection{Our Existence-Life and Death, Our Undeniable Destiny and a Thrilling Future}

The phenomenon of death transcend beyond the immediate and long term experience, for while there is engagement in time, death has a continual presence but no end point. Death is both infinite and recurrent, and thus an ever evolving process and circumstance. In conversations on death we may find the rational (and perhaps the irrationality) of death in the leverage of everydayness of life. In that case, the more traditional societies must explore our lives (particularly our everyday experiences in a modern world) and our future and in turn discuss death - this is part of our being. It would be futile to pretend that we are immune to death, or that we are not aware of it. Jirásek, Oborný and Hurych (2018:3) expound this reality:

So, we are included in the question about our being. We ask because of ourselves and from the position of our situation. And, if our being is temporal, then the categorical determination of all human experience is done by its temporality. Our being is included in the present. The past means throwingness (we are thrown into the life situations which were not selected by us). The future means the possibility of scheduling (we can decide what we focus on and which way we want to live in).

It is perhaps justified as argued by Jirásek, Oborný and Hurych to say that we need to authentically engage our own anxiety about death. This would awaken in us the truth and reality of the mystery of life and death in order to comprehend our situation, no matter how temporal life is. Life and death, the fear and anxiety, and perhaps the misfortunes of immortality are interlinked with our traditional-cum-contemporary psychology in that our life is greatly a study of ourselves. Death is a part of our circumstances, just as life remains connected with us, and just as we aim in various ways such as philosophy and psychology to expand our knowledge of ourselves and our 
world. This requires a transformation of understanding death as converse of life to continuity as demonstrated below:

Figure 6. Life $<>$ death to life (start)
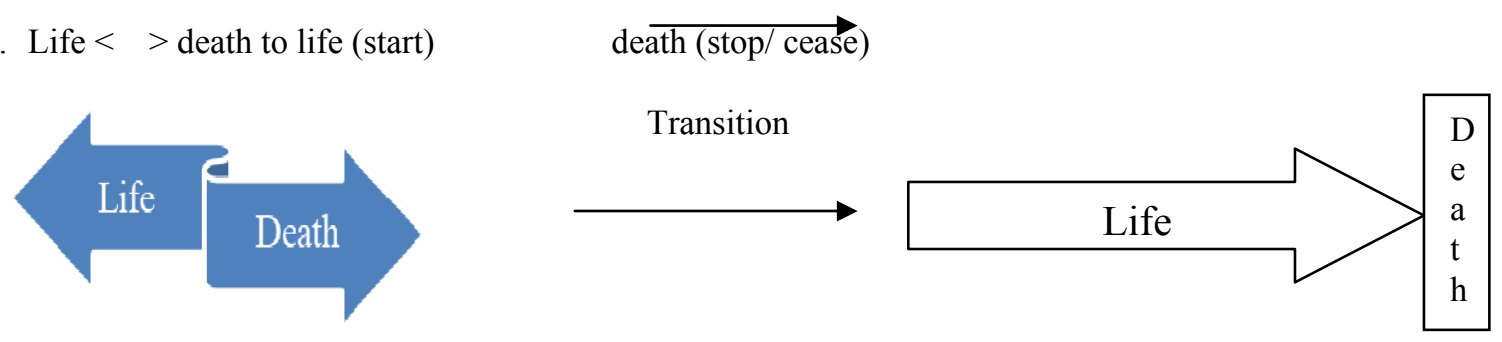

The new transformation involves a change in attitude in which people understand and accept that life culminates in death. The time pivotal roles (Figure 4) are thus synchronised with the life death process and logic, rather than fear and anxiety about death. This way, counselling practitioners will be able to assist clients to absorb the loss perpetuated by death. Subsequently, clients can adapt to the changes death unleashes in unique ways. On the other hand, social workers must be prepared to provide psycho social support for such clients in order for them to face the realities of death and subsequent loss from a much stronger position. The unique collaboration between counsellors, social workers and medical practitioners will in turn provide a strong holistic approach for effective handling of death and its resultant outcomes not only for clients who are dying but for bereaved families agonising at the loss and trauma of death.

Let us be philosophical and ask: what can we say or do, about death? This is because admittedly, we have a present (life and death as inevitable) and a future (death-that awaits us); this is our way of being. Therefore, an understanding of the process of life and death is fundamental for increasing our understanding of both our existence and our being human. The importance becomes even more urgent when one realizes the topic of death is one of a kind, especially for many people who do not want to reckon with the reality of death leave alone talk about it. Yet, our perception (consciously or unconsciously) of life and death is part of our existence. Jirásek, Oborný and Hurych (2018:4) summarize it thus:

The perception of our mortality and relating to our very last limit enable us to schedule our possibilities of being. Any experience which is chosen this way gives evidence about the way how we manage our possibilities and how we exist in the authentic way. Only this terminality (knowledge of existence of our death) can help us to reach a better understanding of ourselves and a possibility to recognize the modus of our freedom. We are free in our being and in a care of it, in the possibilities how to schedule our lives, and in the modes of experience which we choose. If we fall into the "world of things" (a focus on "what is spoken", "what is on", "what is recommended" - that means falling into "the They") we could not consider the "authentic" experience because we would not be related to the ontologic being but just to the ontic one.

This is a near reality cryptic reflection on our existence. It signifies an inextricable life-death connection. It is correct to state that we are alive, nevertheless there is a sequence, consequence that puts a 'but', death. Death has a powerful influence on our lives and that of others and it is in the everydayness of our lived experience, a showing of relational play in life and living, happiness and sadness, joy and disappointment and this is summed up in life and death, culminating often in pain and sorrow. We would all possibly want to avoid death, but philosophically, death does not want to avoid us - it awaits us, it sits right at the end of the tunnel sometimes waving at us, or vibrates like a wild storm or quietly waits like a crocodile in still deep waters. The end results are the same, the inevitability of death. Death is multi-faceted, it has the imminence within which lies the fear and anxiety. In all, it is unavoidable and thus a part of life rather than the end of it. But again, we cannot annihilate the human spirit; instead, we must continue to exist thus edifying our human mortality.

In the final section of this paper, we suggest an extension on knowledge from current competencies to coping (Figure 7).

\subsection{Distance yet so Aptly Present: Therapeutic Practitioners, Practice and Death}

As earlier mentioned, dealing with death in our contemporary societies is a venture that is multi-disciplinary in several aspects for holistic outcomes in managing potential effects and implications of death including grief, loss and emotional instability. Medical personnel including doctors, nurses and other clinicians who handle patients at different stages of their illness require other caregivers and practitioners such as counsellors, psychologists 
and social workers for holistic intervention and social support of their patients and/or clients particularly those battling physical illness or even those who may be terminally ill.

Counselling psychologists and general counselling practitioners must be able to frame and respond to questions and concerns about death. we would like to posit death as far as modern medicine is concerned in four related ways: (1) The need to preserve life (medicine, drugs and information technology - physiological, social, spiritual, philosophical and psychological); (2) Prolonging of life (if not an escape from death - physiological and philosophical); (3) Eradication of pain (reduction of pain and suffering - physiological); and, (4) Coping with the pain of death (fear, anxiety and stress - social, spiritual, philosophical and psychological). Of course, the four are all in the same realm and this signifies an inextricable life-death connection and thus it is perhaps best to state that counselling psychologists will be preoccupied with the feelings and emotions. Jointly and in collaboration with the medical personnel, counselling practitioners and social workers must embrace a concise effort to define health and wellness and in turn identify and clarify the art of coping and healing from the modern science of medicine. In this regard, Crist (2018:7) opines that health is not a state of utter stillness, immovability, or inactivity; rather it is a general feeling of well-being. It is a rhythm of life, a continuous movement in which equilibrium is disrupted and must re-establish itself, and manifests its own robustness when we are able to manage these disruptions but not without pain:

Health, however, is not a state of utter stillness, immovability, or inactivity, rather it is a general feeling of well-being, whereby we are open to new things, ready to embark on new enterprises and, forgetful of ourselves, scarcely notice the demands and strains which are put on us. This is what health is. However, because health involves a condition of an active, engaging, and rewarding kind of being in the world, health becomes something concealed from us and difficult to pin down. What reveals our own health to us are precisely those recalcitrant matters which intrude into our human experience of life. Health, then, is a rhythm of life, a continuous movement in which equilibrium is disrupted and must re-establish itself, and manifests its own robustness when we are able to manage these disruptions without a complete numbing of pain.

Health in this instance is a kind of open and engaging sensibility towards life, and of course death. We do want to proclaim death as both threatening and disruptive but again, death is a finitude and thus modern science should not be construed as decreeing existentialism. Incidentally, health and wellness are related to coping and healing because they have a complementarity component. All in all, psychologists must be wary of the modern medicine's combative disposition towards (or doing away with) pain, suffering and of course death. In that case, the shift in focus and healthy living amidst death must take cognizance of the psychological variables, as well as the transition going on in society and in the world but at the end bring about amicable understanding of both life and death. This transformation is represented in Figures 6 and 7.

Social workers on their part will largely provide a conducive environment where clients with terminal illness or those about to die can be provided psycho-social and palliative care in a dignified manner but not as people condemned by their current state of illness. Social workers can also be handy for the families of such clients by giving them hope and inspiring them not to focus or concentrate so much on the helplessness of their situation but be pillars of support and a hope of changing their desperation into a turning point for their ailing family member(s). In addition, social workers can serve as strong advocates for the rights of the ailing client and/or their mourning families in the event their loved one is no more. The rights of clients in physical illness and their grieving families can best be championed by social workers for a comprehensive well-being, recovery or acceptance of the reality should death be the final outcome of physical illness. The social dimensions of illness and death is thus a major focus for social workers dealing with illness, loss and grief, death and bereavement. Linking up such affected clients with corresponding or needed resources is another critical role of a social worker. A good example of such a resource are pastoral teams to provide the client with the much needed pastoral and/or spiritual care which can further enhance ongoing interventions to cope with the realities of looming death or grief and mourning following bereavement. The competencies are illustrated in Figure 7. 


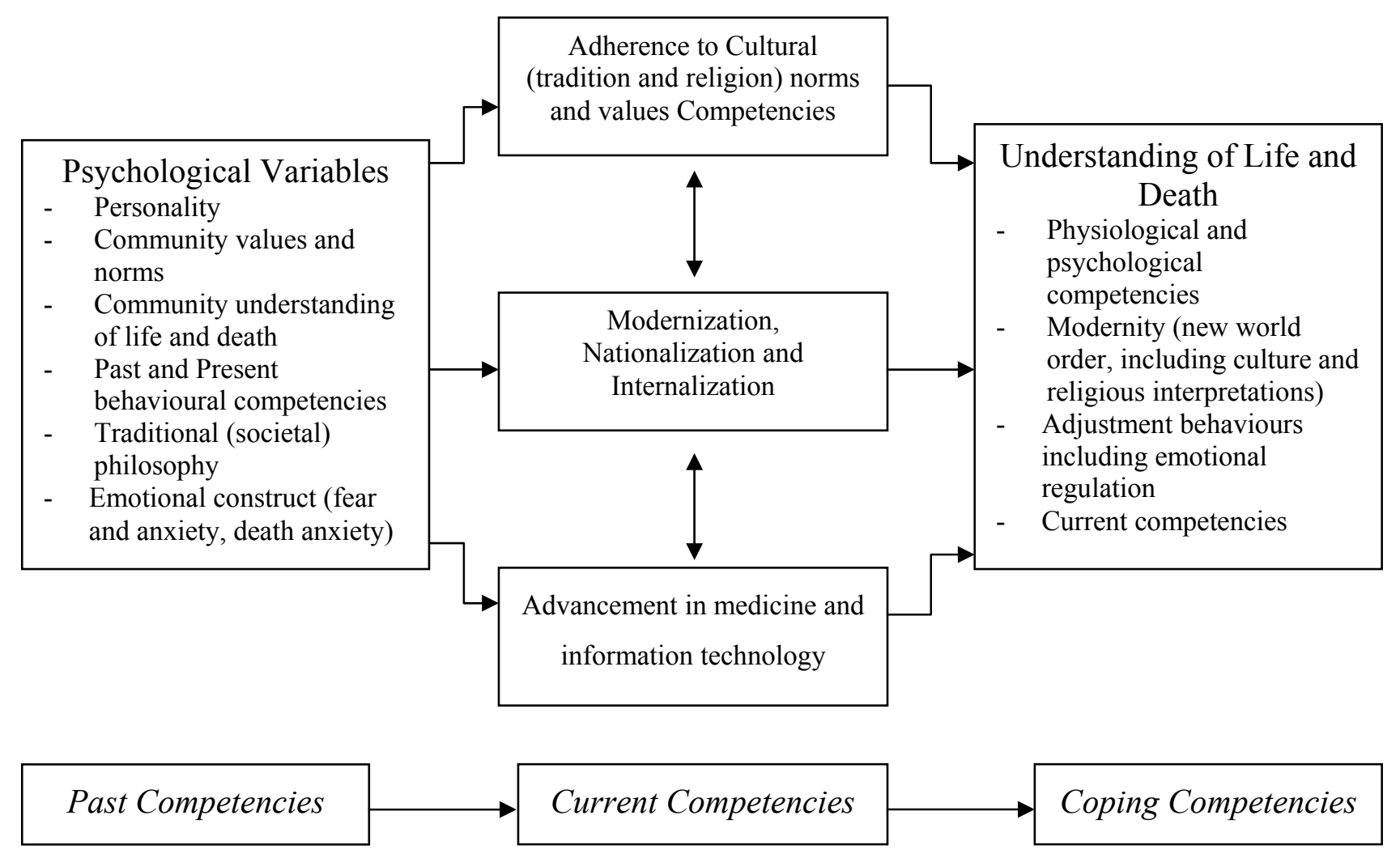

Figure 7. Behavioural Competencies of Life and death in Traditional-cum-Contemporary Societies

The suggested shift in behavioural competencies of life and death from past to current and into coping is a modification and not an alternation. Emotional constructs such as fear and anxiety (in this instance death anxiety) is incrementally improved to emotional regulation to enable deal with anxiety disorders. This is because we do not want to prescribe to the community how to cope with (life and) death but simply expurgate on the going-on in society. Again, this is within the hermeneutic phenomenological framework of interpretation of life and death experience rather than a historical description but within the cultural phenomena. As background, it is still important to highlight that communities varied: they have different histories, traditions, beliefs, contexts and contemporary dynamics. These conditions will affect their conceptualization (and of course susceptibility to) death and thus vulnerability to certain psychological impacts. There are also the personality differences while other factors such as religion and resilience will also differ among individuals. Hence, a traditional-wide analysis risks over generalizing and over simplifying the complex web of life and death as specifics underlying causal, effect and symptomatic dealings require additional interpretation.

Before we conclude, we wish to highlight the fact that the increasing number of psychological and social interventions involving mental health have led to positive mental health (Holtmaat et al., 2018; Keyes, 2005; Ryff \& Singer, 1998). Purposeful positive mental health in this instance in dealing with life and death, is a construct that appropriately is multifaceted and should incorporate knowledge competencies in all sectors (including tradition, religion and modernity, Figure 5). This new construction which is a transition (Figures 6 and 7) can be represented as follows: 


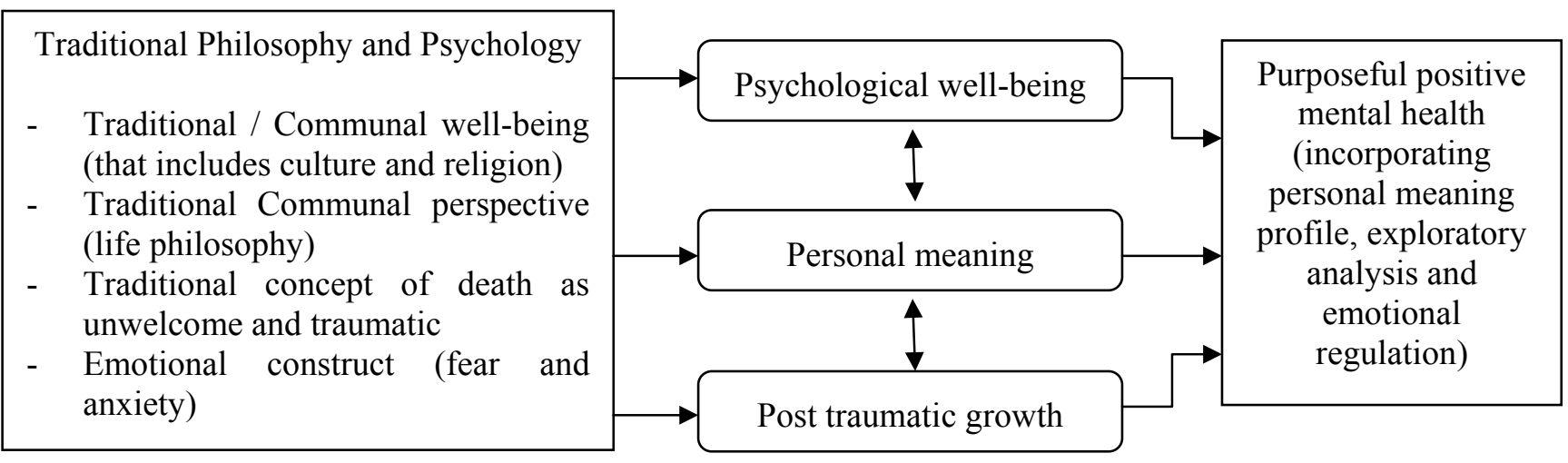

Figure 8. Modern Construct of Purposeful Positive Mental Health

Such knowledge of need for psychological well-being and enhanced personal meaning integrates post traumatic growth. It is important for both practitioners in counselling psychology and social workers as well as their clients for the purpose of redesigning effective coping strategies (Figure 7 and 8) with strengthened regulations on positive mental health. This enables a more general focus on the quality of life rather than an emphasis on psychological distress, an adjustment to life as well as an experiencing of a sense of meaning in life and death.

There is need for distributing collective ownership of the life-death process as basic obligations and discharging them in a proportional modern fashion to professionals. The modern society approach would include clinical professions (doctors, surgeons, nurses) as well as helping professionals that include therapists, social workers and other care-givers. The conscious motivation is comprehensive health care $(\mathrm{CHC})$ that recognizes various needs such as physiological (medical), psychological (counselling), social (social workers), spiritual (clergy) and general well-being (informal care givers) in order to provide the best care possible. The purpose is to enable positive mental health outcomes even in the most difficult circumstances such as death. Death then is not so distanced, and counselling psychologists and social workers can then be strong enough to philosophically embrace and practically assist clients facing the reality of death.

\section{Conclusion}

This paper has attempted to rationalize the traditional African concept of life and death (that includes the hereafter) and the present modernized (in the context of medical and information advancement, new religion such as Christianity or otherwise) notion of life and death. The aim is to enable an understanding of loss and grief as well as ease the grieving process. In the past, people were born and died at home with their families nearby. Most people died in their own beds. Death was considered a natural part of the life cycle. Today most deaths occur in hospitals or hospice; the dying is often surrounded by medical personnel instead of family members. Death has become a remote but constant subject that many people would prefer to avoid discussing. Modernization and internationalization include a new form of education, scientific and technological advancement globalization, urbanization, other (new) religions and these in turn seem to be modifying and affecting the African concept of life, death and the hereafter Using the hermeneutic phenomenology, it is noted that the dominant (traditional) culture has utmost control of the mind and society, and thus an impact on life and death processes.

Firstly, it can be deduced that both the traditional (predominantly African) concept of life and death has aspects of interception with modern, particularly Christianity based on certain point's basis of life as follows: (a) God is the originator of life; and, (b) life does not end at death. Death is a transition and transformation from the physical into the spiritual world. Secondly, there are aspects of diversity in that in the African traditional concept, the ancestors are still involved in the communal lives of their people which is different in Christianity. This is because the traditional communal living involving societal relationships is replaced by a communion with God in Christianity. Thus, traditional societies are based on certain religious traditions, beliefs and laws that contend death in such magnitude that it becomes difficult to individual understanding.

There is a direct relationship between life and death and this can be explained by means of a phenomenological shift in which psychologists and philosophers assist any attempt to conceal the structure of the two as too 
distinctive phenomenon. In order to effectively carry out such a healthy procedure, it is necessary to get rid of the fears, anxiety and myths about death that only conceals its structure from our consciousness, and instead create a false illusion about death. Additionally, medical and information technology adds to this illusionary notion that life can be prolonged, and death can be avoided - to the extent this is logical and realistic should be applauded and is noteworthy. In this connection, we especially in the traditional-cum-contemporary societies need to embrace the concept of death as 'the other' part of life, in fact the culmination of life.

Death becomes a referent, a prototype that reproduces itself in several of patterns of our life, of a sensual given existence rather than hidden, a reality and not an illusion. At the same time, it is both necessary and possible to give life a meaning and promote healthy living thus differentiating between death as final and untimely events leading to death. This is a transformative form of phenomenological reduction of life and death and not the suspicion of the destructiveness rather than the destiny of life. This denotes a new (reviewed) structure of consciousness which is a form of reflexive acts of consciousness not related to the fear of death; it is content in context, and not circumstantial. Such a form of consciousness and realization of the imminent (finitude) of death is by itself fulfilling in that it changes the perception of the life - death content.

In our own view, this involves both studies and carrying out incessant phenomenological shifts in the orientation of death, in the form of consciousness and in a life meaning-generating construction. This is the workings of philosophy and psychology that interacts with social life. Studies of life and death will adopt a holistic and multidisciplinary approach that encompasses the critical care giving professions for clients and families dealing with death related issues. Such professions include counselling psychology and social work both of which can intervene jointly or at different points in time during the period for which the client is under their care. In essence therefore, there is need to strengthen corresponding counselling and social work intervention skills for effective handling of death related needs and issues. This must be done keeping in mind the fact that the clients involved still have their dignity and respect which must be prioritized and honoured even as interventions for their situation unfolds.

\section{Acknowledgments}

We are grateful to the University of Nairobi for the opportunity to serve as Senior Lecturers in the Departments of Psychology and that of Sociology and Social Work.

\section{Declaration of Interest}

The authors declare no conflicts of interest with respect to the authorship and/or publication of this article.

\section{References}

American Psychiatric Association. (2013). Diagnostic and Statistical Manual of Mental Disorders DSM - 5. Washington, D C: American Psychiatric Association. https://doi.org/10.1176/appi.books. 9780890425596

Asuquo, O. O. (2011). A rationalization of an African concept of life, death and the hereafter. American Journal of Social and Management Sciences, 2(1), 171 - 175. https://doi.org/10.5251/ajsms.2011.2.1.171.175

Becker, E. (1973). The Denial of Death. New York: The Free Press.

Byock, I. (2002). The Meaning and Value of Death. Journal of Palliative Medicine, 5(2), 279 - 288. https://doi.org/10.1089/109662102753641278

Crist, A. (2018). A Hermeneutic Approach to Pain: Gadamer on Pain, Finitude, and Recovery. Journal of Applied Hermeneutics, Article, 10, 1 - 11.

Dadfar, M., \& Lester, D. (2017). Religiously, Spirituality and Death Anxiety. Austin Journal of Psychiatry and Behavioural Sciences, 4(1), 1061.

Dobrosavljev, D. (2002). Gadamer's hermeneutics as practical philosophy. Philosophy, Sociology and Psychology, 2(9), 605 - 618.

Dreyfus, H. (1991). Being-in-the-world: A commentary on Heidegger's Being and Time, Division I. Cambridge, Ma: MIT Press.

Finlay, L. (2009). Debating phenomenological research. Phenomenology \& Practice, 3(1), 6 - 25.

Firestone, R. E., \& Catlett, J. (2016). Beyond death anxiety: Achieving life-affirming death awareness. New York: Springer Publishing Company.

Frankl, V. (1986). The Doctor and the Soul. trans. Richard and Clara Winston. New York: Vintage Books.

Fuchs, T., \& Pallagrosi, M. (2018). 'Phenomenology of Temporality and Dimensional Psychopathology'. 
Springer International Publishing AG, part of Springer Nature 2018, 287- 300. https://doi.org/10.1007/978-3-319-78202-7_10

Gadamer, H-G. (1996). The enigma of health: The art of healing in a scientific age (J. Gaiger \& N. Walker, Trans.). Stanford, CA: Stanford University Press.

Heidegger, M. (1962). Being and Time. trans. John Macquarrie and Edward Robinson. New York: Harper Collins.

Heidegger, M. (1976). What Is Called Thinking? (Trans. Fred D. Wieck and J. Glenn Gray) New York: Harper.

Holtmaat, K., van der Spek, N., Lissenberg-Witte, BI, Cuijpers, P., \& Verdonck-de Leeuw, IM. (2018). Positive mental health among cancer survivors: overlap in psychological well-being, personal meaning, and posttraumatic growth. Support Care Cancer, https://doi:org 10.1007/s00520-018-4325-8.

Jirásek, I., Oborný, J., \& Hurych, E. (2018). The authentic and inauthentic sport in the hermeneutic and phenomenological perspectives. Acta Facultatis Educationis Physicae Universitatis Comenianae, 58(1), 1 11. https://doi.org/10.2478/afepuc-2018-0001

Kafle, N. P. (2013). Hermeneutic phenomenological research method simplified. Bodhi: An Interdisciplinary Journal, 5(1), 181 - 200. https://doi.org/10.3126/bodhi.v5i1.8053

Keyes, C. L. M. (2005). Mental Illness and/or Mental Health? Investigating Axioms of the Complete State Model of Health. Journal of Consulting and Clinical Psychology, 73(3), 539 - 548. https://doi.org/10.1037/0022-006X.73.3.539

Kübler-Ross, E., \& Kessler, D. (2005). On grief and grieving: Finding the meaning of grief through the five stages of loss. New York, N.Y.: Scribner.

Laverty, S. M. (2003). Hermeneutic phenomenology and phenomenology: A comparison of historical and methodological considerations. International Journal of Qualitative Methods, 2(3), 21 - 35. https://doi.org/10.1177/160940690300200303

Malet, P. M. (2013). Attestation and response: Reflection from a hermeneutical phenomenology of capabilities. Trans/Form/Ação, 36(1), 137 - 164. https://doi.org/10.1590/S0101-31732013000100009

Marava. (2015). African Philosophy on the Concept of Time and Its Influence on the View of Death and Afterlife - A Zimbabwean Perspective. International Journal of Philosophy and Theology, 3(2), 87 - 97.

Mbiti, J. S. (1969). African Religions and Philosophy. London: Heinemann.

Nicholl, E., Loewenthal, D., \& Gaitanidis, A. (2016). 'What meaning does somebody's death have, what meaning does somebody's life have?' Psychotherapists' stories of their work with suicidal clients. British Journal of Guidance \& Counselling, 44(5), 598 - 611. https://doi.org/10.1080/03069885.2015.1089430

Njoku, F.O.C. (2002). Essays in African Philosophy, Thought and Theology. Owerri: Clacom,

Nzioka, C. (2000). The social meanings of death from HIV/AIDS: An African interpretative view. Culture, Health \& Sexuality, 2(1), 1 - 14. https://doi.org/10.1080/136910500300831

Pashak, T. J., Justice, M. D., Burns, B. R., Lahar, K. L., Handal, P. J. \& Creech, C. (2018). Separation of Church and Trait: Trait Death Anxiety is Universal, Distressing, and Unbuffered by Worldview in Emerging Adults. Journal of Religion and Health, 1 - 18. https://doi.org/10.1007/s10943-018-0623-1

Peters, L., Cant, R., Payne, S., O’Connor, M., McDermott. F., Hood, K., Morphet, J., \& Shimoinaba, K. (2013). How death anxiety impacts nurses' caring for patients at the end of life: A review of literature. Open Nursing Journal, 7, 14 - 21.

Rice, J. (2009). The relationship between humor and death anxiety. Department of Psychology, Missouri Western State University.

Ryff, C. D., \& Singer, B. (1998). The contours of positive human health. Psychological Inquiry, 9(1), 1 - 28. https://doi.org/10.1207/s15327965pli0901_1

Sloan, A., \& Bowe, B. (2014). Phenomenology and hermeneutic phenomenology: The philosophy, the methodologies, and using hermeneutic phenomenology to investigate lecturers' experiences of curriculum design. Quality \& Quantity, 48(3), 1291- 1303. https://doi.org/10.1007/s11135-013-9835-3

Tillich, P. (1959). The eternal now. In: Feifel, H (Ed): The Meaning of Death. New York: McGraw-Hill.

Trisel, B. A. (2015). Does Death Give Meaning to Life? Journal of Philosophy of Life, 5(2), 62 -81. 
van Manen, M. (2007). Phenomenology of practice. Phenomenology \& Practice, 1(1), 11 - 30.

Wango, G. M. (2013). A Synchronic Hermeneutic Phenomenological approach to Counselling Psychology in Contemporary Traditional Societies. Nairobi: University of Nairobi.

Wango, G. M. (2015). Counselling Psychology in Kenya: A Contemporary Review of the Developing World. Nairobi: Kenya Literature Bureau.

Young, J. (2003). The Death of God and the Meaning of Life. London: Routledge.

Zisook, S., Corruble, E., Duan N., et al. (2012). The bereavement exclusion and DSM - 5. Depress Anxiety, 29,425 - 443. https://doi.org/10.1002/da.21927

\section{Copyrights}

Copyright for this article is retained by the author(s), with first publication rights granted to the journal.

This is an open-access article distributed under the terms and conditions of the Creative Commons Attribution license (http://creativecommons.org/licenses/by/3.0/). 